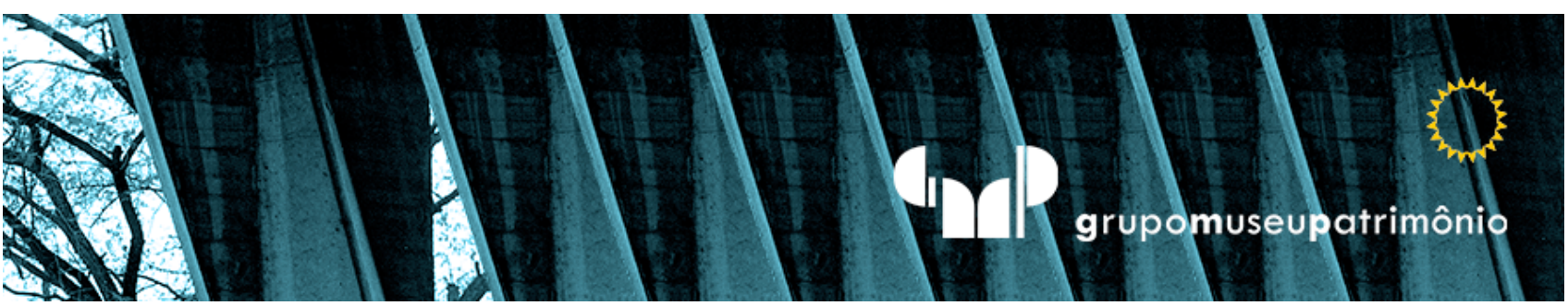

\title{
Vik Muniz: alquimista das Imagens
}

\author{
Vik Muniz: alquimista de las Imágenes
}

\section{Vik Muniz: alchemist of Images}

\section{Agnaldo Aparecido Geremias}

Universidade Presbiteriana Mackenzie, São Paulo, Brasil. agnaldo.geremias@gmail.com 


\title{
Resumo
}

Este artigo traz uma análise sucinta do processo criativo do artista plástico Vik Muniz. Objetiva suscitar reflexões acerca dos significados passíveis de serem apreendidos a partir da observação atenta de suas obras, bem como um diálogo entre elementos de sua trajetória artística e os aspectos teóricos do processo criativo. A ideia é criar uma "fresta" intertextual que estimule a compreensão do tema proposto e a transcendência dos limites da linguagem.

Palavras-chave: Arte. Arte contemporânea. Artes plásticas. Criação artística. Criatividade.

\section{Resumen}

Este artículo presenta el proceso creativo del artista visual Vik Muniz. El objetivo es suscitar reflexiones sobre los significados que se pueden aprehender a partir de la atenta observación de sus obras, así como un diálogo entre elementos de su trayectoria artística y los aspectos teóricos del proceso creativo. La idea es crear un "grieta" intertextual que estimule la comprensión del tema propuesto y la trascendencia de los límites del lenguaje.

Palavras-clave: Arte. Arte contemporaneo. Artes plásticas. Creación artística. Creatividad.

\begin{abstract}
This article presents the creative process of the visual artist Vik Muniz. The objective is to raise reflections about the meanings that can be apprehended from the careful observation of his works and the dialogue between elements of his artistic trajectory and the theoretical aspects of the creative process. The idea is to create an intertextual "gap" that stimulates the understanding of the proposed theme and the transcendence of language limits.
\end{abstract}

Keywords: Art. Artistic creation. Creativity. Contemporary art. Visual arts. 


\section{INTRODUÇÃO}

V

icente José de Oliveira Muniz, mundialmente conhecido como Vik Muniz é um artista visual brasileiro conhecido e reconhecido interna-cionalmente que utiliza em seu processo de criação uma miríade de materiais inusitados. Feijão, açúcar, grãos de café, cartões postais, manteiga de amendoim, chocolate, leite condensado, molho de tomate, gel para cabelo, geleia de frutas e produtos recicláveis são algumas das matérias-primas utilizadas por ele na composição de suas obras. Residente nos Estados Unidos desde a sua juventude, seus trabalhos se encontram expostos nas principais galerias e museus de arte espalhados pelos quatro cantos do planeta.

Por intermédio deste artigo, cujo título foi inspirado justamente nas gratas surpresas provocadas pelos materiais, técnicas, estratégias e curiosidades imbricados no processo criativo de Vik Muniz, intenciona-se não só descrever seu trajeto de criação, mas, sobretudo, suscitar reflexões acerca de algumas das infindáveis multidimensionalidades das artes visuais.

A fim de possibilitar maior concretude ao leitor, acerca do processo criativo do artista, apresentaremos e discutiremos algumas de suas obras, as quais, para além do óbvio valor e importância artística, demonstram, principalmente, sua forte 
preocupação social e com o futuro do planeta. Para tanto, estabelecer-se-á um diálogo entre os elementos de maior destaque da trajetória artística de Vik Muniz e os aspectos teóricos do processo criativo propostos por Mihaly Csikszentmihalyi (2006) e Cecília Salles (1998). De forma proposital, escolhemos não inserir as imagens das obras junto ao texto, intencionando provocar um exercício de abstração e, ao mesmo tempo, estimular o leitor para um possível interesse no aprofundamento acerca do trabalho do artista.

Cabe esclarecer que o intuito desta análise não é discutir o processo de amadurecimento do artista, mas sim destacar os nuances da criação possíveis de serem apreendidos em suas obras; por isso não nos ateremos a uma ordem cronológica, no que se refere ao período de criação.

Antes, porém, de passarmos à apresentação de suas obras, vale destacar, que o principal gatekeeper ${ }^{1}$ da trajetória de Vik Muniz nos domínios da arte contemporânea norte americana foi o crítico de arte do Jornal New York Times, Charles Haggan. Depois de uma matéria publicada por ele no aludido periódico, versando sobre as obras de Vik Muniz que compunham a exposição Sugar Children (falaremos dessa exposição mais adiante), grandes museus como Guggenheim e Metropolitan Museum of Art passaram a requisitar exposições de suas criações. A partir disso, o trabalho de Vik Muniz foi sendo cada vez mais reconhecido e sua criatividade alcançou dimensões mundiais nos domínios da arte contemporânea.

\section{A ARTE E O INUSITADO}

Segundo Sabrina Sanfelice (2011, p. 25), “[...] explorar o horizonte da percepção visual usando materiais incomuns, como serragem, açúcar, areia, papel de parede, jornais ou lixo numa obra de arte não é algo novo, pois Picasso e Braque já o faziam por volta de 1912 em Paris". Embora possa ter se inspirado em tais fontes criativas, Vik Muniz revela em suas obras, além de uma inegável intencionalidade crítica, uma

\footnotetext{
${ }^{1}$ O significado literal do termo Gatekeeper é "guardião dos portões" e de um modo geral representa a pessoa encarregada de filtrar as tentativas de contato de um vendedor com um profissional da alta gestão ou com grande reconhecimento no mercado. Nas artes, o acesso aos domínios que possibilitam ao artista alcançar o reconhecimento de sua produção passa, em grande medida, por um Gatekeeper.
} 
intensa habilidade para perceber potencialidades artísticas em objetos e materiais prosaicamente utilizados no cotidiano, transcendendo seus aspectos puramente utilitários. Essa notável aptidão permite-Ihe expressar uma linguagem visual capaz de trazer à tona perspectivas dialógicas da arte, provocando no espectador um exercício de contemplação entre estético e lúdico, o prosaico e o poético, o belo e o feio, a angústia e a alegria, a racionalidade e a sensibilidade.

A primeira obra que apresentamos traz por título: Lampedusa. Trata-se de uma instalação criada em 2015 e que foi apresentada na Bienal de Veneza. Seu nome é uma referência à Ilha italiana de Lampedusa, alocada no arquipélago das Ilhas Pelágias no Mar Mediterrâneo, onde frequentemente desembarcam refugiados advindos da África e que se valem da ilha como uma espécie de ponte para acesso clandestino à Europa. A instalação apresenta uma gigantesca dobradura, no formato de um barco de papel, elaborada a partir da ampliação de um jornal local, o qual retrata a morte de refugiados na tentativa de uma travessia frustrada.

Assim, nessa obra, é possível reconhecer a postura crítica de Vik Muniz, frente às políticas europeias discriminatórias e higienistas adotadas diante da questão da imigração. A instalação chamou a atenção do público da Bienal, ao recordar a polêmica internacional gerada a partir do episódio da proclamação do chamado "Estado de emergência humanitário", implementado em março de 1991, ocasião na qual milhares de refugiados albaneses deixaram sua terra natal pressionados pela queda do regime comunista em seu país e aportaram no litoral italiano. Naquela ocasião, ao invés de serem acolhidos em sua angústia, os albaneses foram imediatamente detidos e, depois de várias semanas de confinamento num estádio de futebol, foram repatriados para o seu país de origem, sem que fosse reconhecida sua condição jurídica de refugiados (GARCIA, 2014). Para a autora,

Esse é o evento emblemático que marca a nova orientação política italiana no que se refere aos temas imigração, refúgio e asilo, em consonância com os princípios considerados como fundamentais pela União Europeia no combate ao fluxo massivo de pessoas em seu interior, entre os quais destacam-se a militarização das fronteiras, a detenção administrativa e leis de imigração cada vez mais repressivas, punitivas e de amplo caráter discriminatório. (GARCIA, 2014, p. 235) 
Desde então, essa é uma ação dos governos da Comunidade Europeia que vem sendo reiteradamente implementada, como forma de cercear o ingresso de refugiados no país. A aludida ação, travestida de ação humanitária, apresenta-se na realidade como uma atitude segregacionista e de desrespeito aos direitos humanos.

A segunda obra aqui abordada, Jonh Lennon, revela a imagem do famoso ex-Beatle tendo os contornos de seu rosto e cabelos elaborados com grãos de café torrado, enquanto seus óculos são representados por duas xicaras cheias de café. A obra se destaca pela simplicidade, haja vista ter sido composta exclusivamente a partir de uma única matéria-prima, representada a partir de dois de seus principais estados físicos (o grão e a bebida). Ambiguamente, este mesmo fator revela toda complexidade da proposta, isto é, o desafio de se constituir a imagem do astro do rock, valendo-se apenas das aludidas e escassas opções materiais. Uma análise ainda mais aproximada do processo criativo imbricado na obra permite-nos perceber a profunda relação entre o minimalismo ${ }^{2}$ e, concomitantemente, a mensagem subliminar que ela carrega, uma vez que existem histórias acerca de que um amigo dentista teria supostamente apresentado a droga LSD aos Beatles, colocando-a secretamente em suas xícaras de café. Boato ou não, o fato é que um dos maiores sucessos da banda inglesa foi justamente a música Lucy in the Sky with Diamonds, cuja sigla é a mesma que nomeia a aludida substância psicoativa.

Outra obra de Vik Muniz, que coincidentemente retrata a imagem de Jonh Lennon, apresenta, além da admiração que tem pelo ídolo do rock, sua habilidade para compor processos criativos a partir do estabelecimento de parcerias. Em Memory Rendering of John Lennon in Manhattan (1995), Vik Muniz retrata a imagem de Lennon trajando uma camiseta com a inscrição "New York City", cidade onde tragicamente viria a ser assassinado. A curiosidade da obra está no processo a partir

\footnotetext{
${ }^{2}$ Segundo a Enciclopédia Itaú Cultural, "O minimalismo se refere a uma tendência das artes visuais que ocorre no fim dos anos 1950 e início dos 1960 em Nova York, alçada a principal centro artístico com o expressionismo abstrato de Jackson Pollock (1912-1956) e Willem de Kooning (1904-1997). [...] enfatiza formas elementares, em geral de corte geométrico, que recusam acentos ilusionistas e metafóricos. 0 objeto de arte, preferencialmente localizado no terreno ambíguo entre pintura e escultura, não esconde conteúdos intrínsecos ou sentidos outros. Sua verdade está na realidade física com que se expõe aos olhos do observador - cujo ponto de vista é fundamental para a apreensão da obra -, despida de efeitos decorativos e/ou expressivos".
} 
do qual o artista se valeu para sua produção. A imagem que originou a obra refere-se à foto publicada no livro The Best of Life $^{3}$. A edição trazia uma coleção de retratos muito conhecidos produzidos pelos mais respeitados fotógrafos do mundo para a revista Life. Vik Muniz adquiriu um exemplar numa das tradicionais vendas de garagem que os americanos realizam periodicamente. Ocorre que o livro, tido com muito carinho pelo artista, acabou sendo perdido. Num exercício artístico que teve como ponto de partida suas recordações acerca das fotos publicadas naquele livro, Vik Muniz passou por muito tempo tentando recompor, por intermédio do desenho, as fotos daquela publicação, dentre elas a aludida imagem de Jonh Lennon em Manhatan. Valeu-se, para isso, exclusivamente de suas memórias e das memórias de amigos e conhecidos, conforme descreve Sanfelice, ao citar Edemar Ferreira:

De acordo com Edemar Ferreira, no livro Arte Contemporânea, Vik também interrogava pessoas para ajudá-lo a redesenhar aquelas fotos famosas só com o uso da memória que tinham delas. A cada nova lembrança, novos detalhes também eram acrescentados nos desenhos (com diferentes materiais, como lápis, caneta, giz de cera). A ideia era criar uma imagem baseada somente na memória coletiva que essas imagens tinham causado ao longo do tempo pela repercussão e visibilidade que alcançaram, como a foto feita de John Lennon. (SANFELICE, 2011, p. 63)

A autora exibe também as dificuldades enfrentadas por Vik Muniz no desenrolar do trabalho artístico, demonstrando sua criatividade para a invenção de estratégias e ferramentas que viabilizassem a conclusão da obra.

[...] apesar de todo o esforço para que os desenhos ficassem parecidos com as fotos originais, eles estavam rabiscados, marcados pelo tempo e as inúmeras mudanças que foram acrescentadas gradualmente. Foi, então, necessário, criar uma técnica para que essas imagens pudessem ser expostas e despertassem no espectador uma noção maior de veracidade. Vik fotografou os desenhos usando papel, filtro (halftone) e técnica (soft focus) que permitiram uma maior granulação da imagem, dando-Ihes um aspecto esfumaçado, ocultando os traços e rabiscos dos desenhos. (SANFELICE, 2011, p. 64)

\footnotetext{
${ }^{3}$ O melhor da Life - revista americana, criada em 1883 e que existe até os dias atuais.
} 
Salles nos apresenta uma discussão sobre essa forma híbrida que permeia o processo criativo, cunhando o que ela chama de um "percurso organicamente semiótico":

Estamos assistindo a uma ampliação dos "espetáculos" artísticos que não limitam sua materialização a uma determinada linguagem. [...] Os artistas não fazem seus registros, necessariamente, na linguagem na qual a obra se concretizará. Ao acompanhar diferentes processos, observa-se na intimidade da criação, um contínuo movimento tradutório. Trata-se, portanto, de um movimento de tradução intersemiótica, que, aqui, significa conversões ocorridas ao longo do percurso criador de uma linguagem para outra [...]. (1998, p. 114-115)

Além do insight que permitiu à Vik Muniz perceber novas possibilidades de utilização de suas imagens, manipulando-as e submetendo-as a um verdadeiro processo de retroalimentação, destaca-se sua descoberta acerca das riquezas e significados possíveis de serem produzidos a partir das parcerias, do envolvimento dos sujeitos e/ou protagonistas de suas obras no processo de criação. Assim, mister reafirmar, além da criatividade intrínseca, a habilidade apresentada pelo artista na construção de processos coletivos, nos quais as parcerias soam como constitutivo primordial para o alcance dos resultados.

Com a obra Double Mona Lisa (Peanut Butter and Jelly), Vik Muniz apresenta uma releitura da clássica obra de Leonardo da Vinci, feita a partir de dois materiais inusitados, ou seja, geleia de frutas e manteiga de amendoim.

Muniz nos mostra que as coisas nem sempre são o que parecem e a maior parte daquilo que sabemos, só sabemos através da representação, o que não deixa de ser, também, uma ilusão. De longe, só mais uma representação da Mona Lisa, de Leonardo Da Vinci, mas, de perto, muita geleia e pasta de amendoim. (SANFELICE, 2011, p. 93)

Num processo de autocrítica acerca dessa particular criação, Vik Muniz anuncia: “A arte é sobretudo a habilidade de olhar para uma coisa e enxergar outra". Tal consideração demonstra seus "olhos para ver", isto é a capacidade criativa de enxergar num material inesperado um potencial artístico e inovador, uma “Orientação para a descoberta, ou a tendência de encontrar e formular problemas 
onde outros não os viram [...]" (CSIKSZENTMIHALYI, 2006, p. 14, tradução nossa), um elemento de destaque da sensibilidade de Vik Muniz, capaz de ser percebido também na série de criações intitulada Sugar Children (Crianças de Açúcar), datada de 1996, e que foi responsável pela sua fama internacional.

[...] Vik Muniz deu início a uma técnica padrão encontrada em quase todos os seus trabalhos depois da série feita com açúcar: o uso de diferentes materiais, inusitados ou até mesmo corriqueiros demais, para a formação plástica de sua obra posteriormente transformada em fotografia. A importância desse trabalho não está, portanto, centrada apenas no motivo que o fez ficar conhecido, mas, principalmente, na descoberta de um tipo de "hibridismo" que poderia tornar seus trabalhos obras que chamavam a atenção dos críticos, dos leigos e se tornavam interessantes e rentáveis por conta de uma técnica que não se restringia nem somente às limitações que impõem as lentes ou ao simplesmente plástico. (SANFELICE, 2011, p. 117-118)

A exposição é composta por imagens de crianças caribenhas pertencentes às famílias pobres daquela região que, na ocasião, trabalhavam na lavoura da cana. Vik Muniz fotografou aquelas crianças e depois recompôs os contornos das imagens fotográficas sobre papel preto, usando como matéria-prima o açúcar. Um aspecto intrigante adotado por Vik Muniz durante o processo de criação dessas obras é que "[...] à medida que acabava de fazer cada retrato, ele despejava o açúcar num pote de vidro e colava na frente a fotografia original, como se fosse um rótulo" (SANFELICE, 2011, p. 120). Esses potes foram expostos junto às imagens das crianças, numa atitude a partir da qual podemos inferir inúmeros significados. Um deles, talvez seja a intencionalidade de associar a imagem do sujeito, do protagonista de cada figura da obra com o produto, no caso o açúcar, provocando, talvez, no observador, a tomada de consciência acerca da perversidade do capital, que na busca incessante pela produção, pelo lucro, submete, inescrupulosamente, vidas humanas ao seu regime selvagem de exploração.

A riqueza conceitual desse trabalho reside na ambiguidade traduzida pelas imagens: a doçura do açúcar frente ao amargor da vida de trabalho na lavoura, a pureza das

\footnotetext{
4 "Discovery orientation, or the tendency to find and formulate problems where others have not see any $[\ldots] "$.
} 
crianças, em face das agruras impostas pela exploração de sua mão de obra, algo que estirpa-lhes a oportunidade de viver a infância de forma plena.

Numa entrevista concedida ao site Cultura Genial, as palavras de Vik Muniz traduzem sua sensibilidade frente a essa questão social:

O Sugar Children tem muito a ver com a fotografia, já que o açúcar é um cristal e a fotografia é um cristal prateado exposto à luz. É uma série pontilhista feita com açúcar sobre papel preto e depois fotografada em prata de gelatina. Isso desencadeou algo muito importante. Em 1992, passei as férias na ilha de St. Kitts e brincava com as crianças locais em uma praia de areia preta. Estas eram crianças de plantações de açúcar. No meu último dia eles me levaram para conhecer seus pais e me surpreendeu o quão tristes e cansados eles estavam. Como essas crianças se tornaram esses adultos? Concluí que a vida tirara sua doçura deles. Esses retratos em açúcar agora estão em várias coleções importantes, mas também na pequena biblioteca da escola infantil de St. Kitts. Eu devo muito a essas crianças. (FUCKS, 2020)

Apesar de estar em férias naquela localidade, o artista não se desvencilhou de sua curiosidade e, ao revelar que brincou com as crianças na praia de St. Kits, admite sua "infantilidade".

Talvez, a característica mais saliente dos indivíduos criativos seja uma curiosidade constante, um interesse sempre renovado por tudo o que acontece ao seu redor. Este entusiasmo pela experiência é frequentemente visto como parte da "infantilidade" atribuída a indivíduos criativos $^{6}$. (CSIKSZENTMIHALYI, 1996; GARDNER, 1993 apud CSIKSZENTMIHALYI, 2006, p. 14, tradução nossa)

Em Che, à maneira de Alberto Korda, o artista apresenta uma imagem do ícone da Revolução Cubana, Che Guevara, elaborada com feijão cozido, uma comida típica cubana. Neste retrato, assim como em outras obras de Vik Muniz, o material utilizado imiscui-se com o próprio conceito da obra. Matéria-prima e conceito tornam-se uma unidade, a qual se decodifica em pelo menos três importantes nuances: o significado cultural, o significado social e o talento do artista, elementos

\footnotetext{
${ }^{5}$ Documento digital não paginado.

6 "Perhaps the most salient characteristic of creative individuals is a constant curiosity, an ever-renewed interest in whatever happens around them. This enthusiasm for experience is often seen as part of the 'childishness' attributed to creative individuals".
} 
que convergem para as perspectivas do "Modelo Sistêmico de Criatividade" apresentado por Csikszentmihalyi.

O mais representativo trabalho de Vik Muniz, ao menos se levarmos em conta sua relação com o contexto brasileiro e sua repercussão para além das paredes das galerias de arte e museus é Lixo Extraordinário (2010), um projeto que motivou uma exposição com repercussão mundial e que deu origem também à produção de um documentário homônimo. A aludida película permite ao espectador conhecer os bastidores da criação de Vik Muniz, gerando uma espécie de "caderno de anotações midiático" de seu processo criativo, algo que pode ser considerado como uma segunda vertente artística da obra.

A criação apresenta o trabalho desenvolvido por Vik Muniz e uma equipe de parceiros no antigo aterro sanitário do Jardim Gramacho, alocado na baixada fluminense. O "Lixão de Gramacho", como era conhecido, foi considerado como o maior depósito de lixo a céu aberto da América Latina, até o ano de 2012 (ocasião em que foi desativado). O filme originado a partir do projeto foi um grande sucesso de público. Aclamado pela crítica, Lixo Extraordinário chegou a ser indicado ao Oscar de melhor documentário e recebeu o prêmio do público nos festejados festivais de Sundance e Berlim. O cineasta responsável pelo documentário, que pode ser considerado como o gatekeeper que permitiu o acesso do artista para um novo domínio representado pelo cinema foi Lucy Walker.

Os principais parceiros de Vik Muniz nessa empreitada artística foram os catadores de material reciclável, que na ocasião atuavam na Cooperativa alocada nas imediações do aterro. Em entrevista concedida ao Programa Starte (2009) do canal de TV por assinatura Globo News, por ocasião da exposição, o artista Vik Muniz fala de alguns significados que apreendeu a partir da experiência com esses parceiros:

O que eles me ensinaram é muito mais significante do que eu pude ensinar a eles. O que eu passei para eles, por exemplo é que existem maneiras de se fazer uma coisa se tornar mais interessante, mais bonita, e aquilo tem imediatamente um efeito na maneira com a qual nós nos vemos. O que eles me ensinaram foram coisas muito mais interessantes, eu tinha uma coisa, uma relação com o lixo, eu ando obcecado com o lixo ultimamente. Existe todo um passado seu, o lixo, é tudo que não está no seu 
álbum de fotografia. Existe o lixo mental, existe o lixo físico, existe o lixo espiritual, imoral. É tudo que você não quer ser realmente. E a gente joga isso fora. Eu fico imaginando se aquilo te seguisse, se você vivesse com aquilo o tempo todo, que efeito aquilo ia ter na sua personalidade, na sua identidade. Agora, essas pessoas, não só elas vivem com o lixo que elas fizeram a vida inteira, como com o de todo mundo. Elas estão no outro lado da sociedade de consumo, e tudo o que a gente joga e não quer mais, eles estão lá recebendo. (STARTE, 2009) ${ }^{7}$

Como ponto de partida, a partir de um processo de criação semelhante ao projeto Crianças de Açúcar, Vik Muniz fotografou os aludidos trabalhadores. Num segundo momento, valendo-se de um enorme estúdio improvisado próximo ao lixão, o artista projetou as imagens resultantes do alto, em direção ao chão, numa escala gigante. No passo seguinte, com a ajuda dos protagonistas das fotos, Vik Muniz reconstruiu as imagens projetadas utilizando como matéria-prima o lixo reciclável coletado no próprio aterro, um aspecto que confere à criação artística sua dimensão coletiva. Como última etapa, Vik Muniz fotografou (Figura 1) as imagens reconstruídas e transformou-as em telas. Estas compuseram o resultado final da obra que seguiu para exposição.

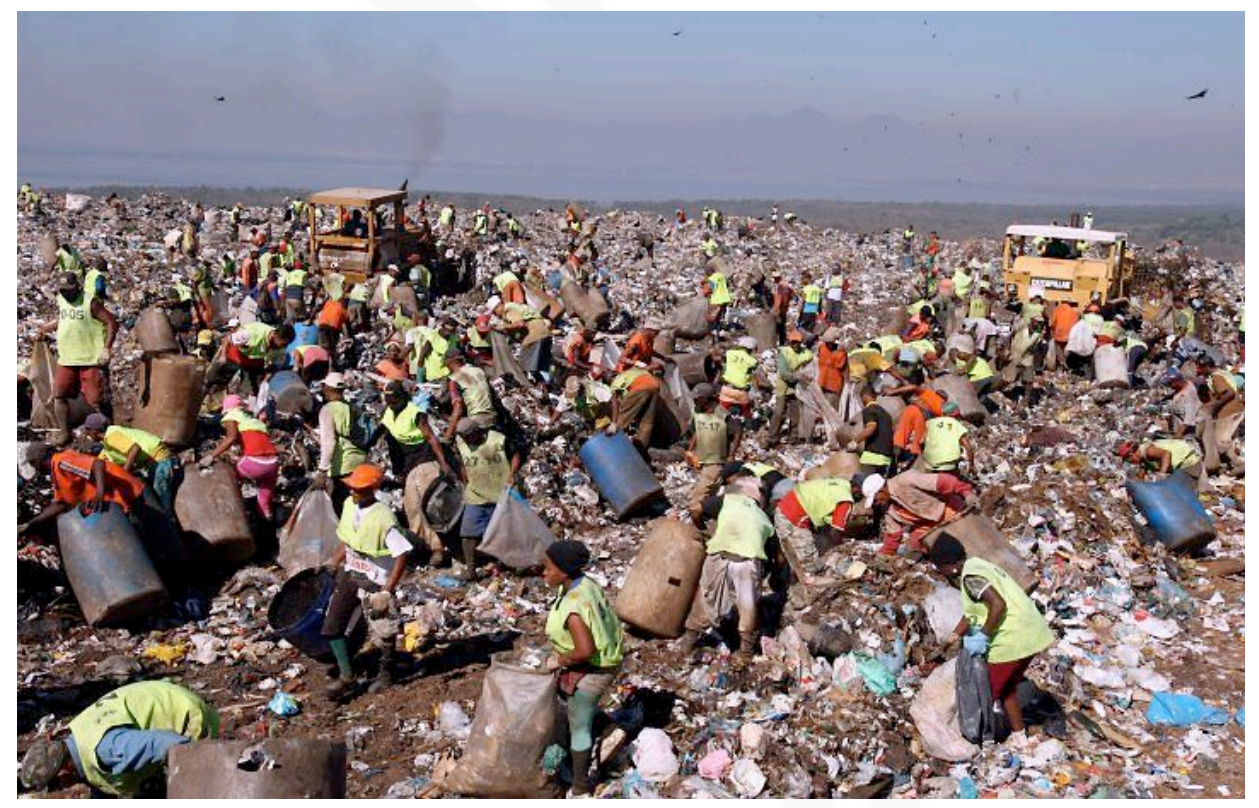

Figura 1: Aterro Sanitário do Jardim Gramacho - RJ Fonte: Site Pinterest. Disponível em: https://br.pinterest.com/pin/403775922813483743/

\footnotetext{
${ }^{7}$ Documento digital não paginado.
} 
Uma das telas de destaque e que traduz toda a intencionalidade do artista nesta particular produção é a obra Marat, uma releitura da obra A morte de Marat (1793), de Jacques-Louis David (1748-1825). A clássica obra retrata o momento da morte do líder revolucionário Jean-Paul Marat (1743-1793), médico, filósofo, teórico, político e cientista, conhecido popularmente como jornalista radical e político da Revolução Francesa. Na releitura de Vik Muniz, o protagonista da foto que deu origem à obra foi o então presidente da Cooperativa dos Catadores do Jardim Gramacho, Tião Santos.

[...] Jean-Paul Marat foi médico, filósofo, cientista, ensaísta, jornalista e panfletário, que ficou mais conhecido por sua participação nos eventos políticos e que na companhia de Danton e de Robespierre levaram a França à Revolução. Marat advogou reformas básicas a favor dos pobres e perseguição constante aos inimigos do povo. Foi assassinado por Charlotte Corday que, disfarçada de colaboradora do movimento, chegou à sua casa e o esfaqueou. [...]. No "eco visual" de um líder revolucionário, que foi assassinado justamente por causa de suas posições em defesa do povo, Vik Muniz faz o seu próprio panfleto revolucionário, seu próprio discurso político transformando, para muitos críticos da arte contemporânea, o luxo da obra de Jacques-Louis David em um simples panfleto de papel reciclável, com uma técnica inegavelmente atrativa [...]. (SANFELICE, 2011, p. 160)

Além dessas importantes reflexões de cunho político provocadas por Vik Muniz e da beleza capaz de levar o espectador ao "estado poético", cunhado teoricamente por Edgar Morin, o que salta aos olhos são as experiências "gestálticas" que cada obra possibilita. Ao fitá-las à distância, o espectador consegue perceber as imagens dos protagonistas das fotos, transformadas por Vik Muniz naquelas obras de arte. Se olhá-las de forma aproximada, todavia, o observador avistará os objetos descobertos arqueologicamente no aterro sanitário durante o processo criativo, podendo acessar reflexões acerca das ambiguidades interpretativas das imagens, uma vez que essas podem possibilitar concomitantemente vários significados. Neste sentido, a poesia proporcionada pela exposição revela, numa mistura entre elementos, ora

\footnotetext{
${ }^{8}$ Para Morin (2017, p. 22), "O estado poético é um estado alterado, nele podemos nos sentir amorosos, admirados, em comunhão, maravilhados, transportados, transfigurados, inspirados".

${ }^{9}$ Para a psicologia, Gestalt é a teoria que considera os fenômenos psicológicos como totalidades organizadas, indivisíveis, articuladas, isto é, como configurações. Para as artes plásticas, trata-se de posicionamento que afirma serem a carga emocional e os conceitos estéticos atributos de uma obra de arte e não do seu espectador.
} 
versicolores, ora monocromáticos, imagens ambiguamente prosaicas das veladas mazelas geradas pela desigualdade social, uma linguagem mítica, um sintoma da miséria cotidiana vivida pelos catadores.

Ao serem imortalizadas em obras de arte, tais imagens carregam o potencial de provocar no espectador emoções que podem ir desde o esperado encantamento estético até o possível reconhecimento das questões sociais geradas pelo consumo (Figura 2). A depender da perspectiva do observador, ora se pode reconhecer o lixomatéria-prima principal daquelas obras de arte - ora se pode perceber sujeitos expostos involuntariamente aos riscos e vulnerabilidades, ironicamente delineados nas telas, pelos espólios da humanidade. O que para alguns poucos soa como rejeitos, para outros tantos se apresenta como meio de vida e objeto de subsistência. Essa forma original e criativa de contextualizar a realidade daquela comunidade pode aparentar, a priori, que seja apenas mais um nuance originado a partir da serindipidade ${ }^{10}$ desencadeada pela busca criativa do artista.

\footnotetext{
${ }^{10}$ Segundo a professora e pesquisadora Regina Lara (2016, p. 5), “O aproveitamento de situações não previstas durante o processo criativo do artista se assemelha à ideia de Serendipidade, um conceito de descoberta científica conhecido entre cientistas como coincidência feliz. $\mathrm{O}$ termo Serendipidade foi criado por um escritor inglês do século XVIII, Sir Horace Walpole, que narrou em uma carta a um amigo a viagem de três príncipes ao reino de Serendip (hoje Sri-Lanka, na Ásia) em busca de um tesouro valiosíssimo. Não encontraram o tesouro, mas no lugar dele conquistaram coisas valiosas que nunca teriam sido descobertas se não fosse a tal viagem".
} 


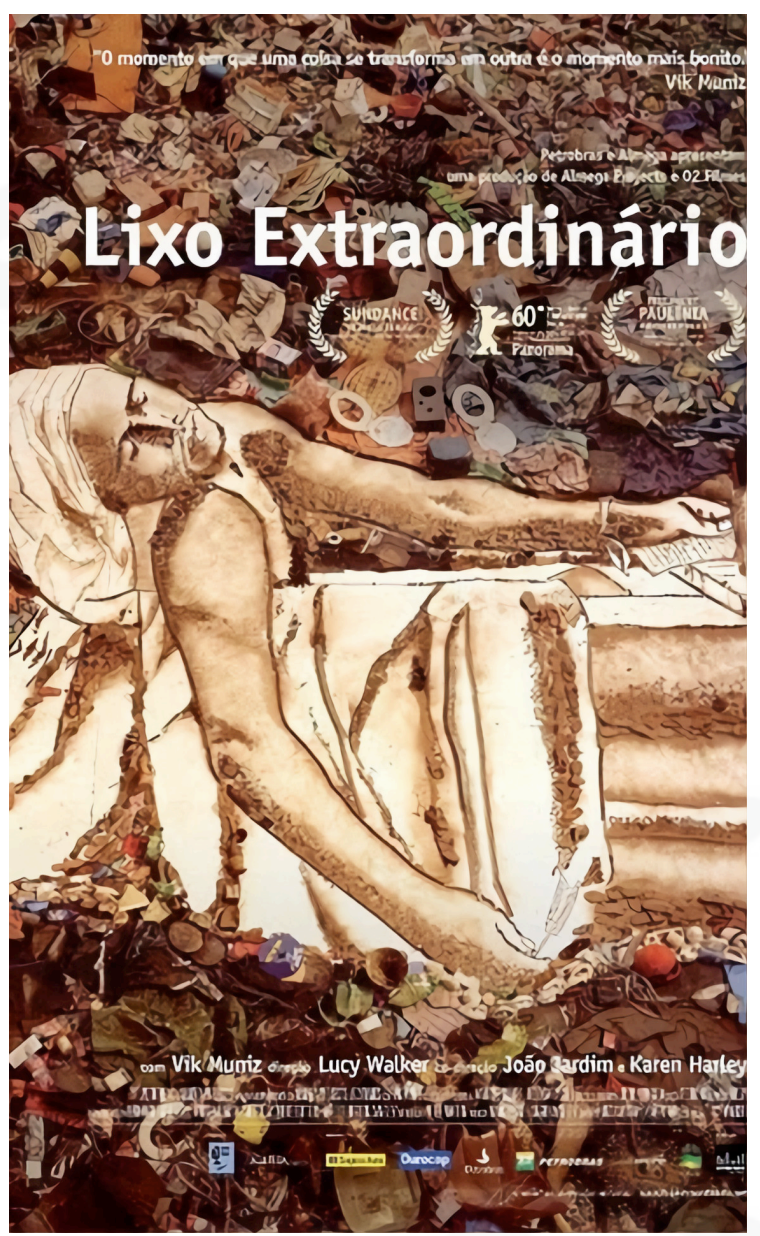

Figura 2: Cartaz de divulgação do filme Lixo Extraordinário. Fonte: Site Cinecartaz. Disponível em: https://cinecartaz.publico.pt/Filme/279866_lixoextraordinario.

Ao analisarmos a obra com maior acuidade, no entanto, é possível perceber intenções que se sobrepõem aos elementos puramente estéticos, isto é, suscitar uma contundente provocação nos espectadores para uma infindável miríade de desdobramentos gerados pelo consumo desenfreado característico do mundo capitalista globalizado. Dentre eles, destacam-se desequilíbrio ecológico, a exacerbação das desigualdades e, sobretudo, a "[...] nova segregação social e racial (ARROYO, 2015, p. 26) posta na agenda política global e nacional. Concomitante e intencionalmente, Vik Muniz concede aos membros da comunidade do Jardim Gramacho (principalmente aos participantes ativos do projeto) espaços reflexivos capazes de estimular a tomada de consciência acerca dos aspectos políticos 
geradores daquelas mazelas e, quiçá, possibilitar um resgate das perspectivas utópicas apresentadas por Karl Mannheim. Para Mazucato,

\begin{abstract}
A ideologia e a utopia fazem parte das motivações coletivas inconscientes, que atuam no sentido de determinar a forma como os indivíduos agem e pensam, e neste sentido Mannheim (1972, p. 67) acredita que "servem para ocultar - em duas direções certos aspectos da realidade social". Há uma identificação de ideologia com "conservação" e de utopia com "mudança", ambas distorcidas da realidade, transcendendo-a, mas em conexão direta com a realidade do grupo dos sujeitos que as pensam. (2013, p. 191)
\end{abstract}

Assim a utopia (ao contrário das equivocadas subversões produzidas historicamente acerca desse conceito, que a asseveram como algo inalcançável) pode soar como estímulo para um movimento coletivo organizado, capaz de se contrapor à ideologia dominante, a ponto de provocar as transformações sociais almejadas e necessárias.

Por fim, a divulgação midiática que compõe a proposta artística potencializa ainda mais esse "ambiente provocativo", caracterizando o todo da obra como uma intervenção artística de grande magnitude, diferenciando-a ante seus trabalhos anteriores, os quais, em grande medida, limitaram-se às exposições.

\title{
CONSIDERAÇÕES FINAIS
}

Ainda que as críticas contemporâneas venham apontando a tendência mercadológica por meio da qual a arte de Vik Muniz parece estar se destacando, haja vista algumas de suas peças terem sido vendidas por centenas de milhares de dólares, não há como negar a importância de seu trabalho e o impacto de suas criações e exposições. Outro aspecto a ser reconhecido é o fato de suas obras terem espaço garantido nos mais importantes museus de arte do mundo, algo que revela a universalidade de sua arte. Por outro lado, considerando que um artista vive do seu trabalho, mister destacar as múltiplas dimensões motivacionais do seu fazer, dentre as quais reside a importância do reconhecimento e valorização de sua produção não só sob os pontos de vista criativo-artísticos, mas igualmente, e em mesmo teor, os econômico-financeiros.

Por fim, como já descrevemos, há que se reafirmar a importância social das criações de Vik Muniz, as quais, a exemplo de Crianças de Açúcar e Lixo Extraordinário envolveram 
parcerias com pessoas do povo, tecendo significados que transcendem os meros constitutivos elitistas da arte, chamando a atenção do público para as questões sociais desencadeadas pelo mundo capitalista globalizado, tais como o consumo exacerbado, o crescimento galopante da pobreza acompanhado da segregação da parcela mais pobre da população e a "desumanização da humanidade". Sua atitude como artista traduz, pelo processo criativo, perspectivas de inclusão e de provocação da humanidade para a tomada de consciência acerca da necessidade emergente da qualificação das relações e dos processos sociais, do respeito à diversidade e, mais do que isso, do reconhecimento da importância social dos sujeitos em detrimento da meritocracia que ignora, marginaliza, segrega e discrimina.

\section{REFERÊNCIAS}

ARROYO, Miguel Gonzalez. O humano é viável? É educável? Revista Pedagógica, Chapecó, v. 17, n. 35, p. 21-40; maio/ago. 2015.

CSIKSZENTMIHALYI, Mihaly. A systems perspective on creativity. In: HENRI, Jane (ed.). Creative management and development. London: Sage Publications; 2006. p. 3-17.

FUKS, Rebeca. As 10 criações mais impressionantes de Vik Muniz. Cultura Genial. Disponível em: https://www.culturagenial.com/vik-muniz-obras/. Acesso em: 12 set. 2020.

GARCIA, Fernanda Di Flora. A exceção é a regra: os centros de detenção para imigrantes na Itália. REMHU - Rev. Interdisciplinar da Mobilidade Humana, Brasília, Ano XXII, n. 43, p. 235-250; jul./dez. 2014.

LARA, Regina. Acasos, serendipidades e insights nos processos criativos de artistas visuais. Revista Tríade, Rio de Janeiro, v. 1, n. 2, p. 1-15; jun. 2016.

MAZUCATO, Thiago. Ideologia e utopia em Karl Mannheim. Revista Sem Aspas, [S. I.], v. 2, n. 1, p. 187-195; 2013.

MINIMALISMO. In: ENCICLOPÉDIA Itaú Cultural de Arte e Cultura Brasileiras. São Paulo: Itaú Cultural; 2021. Disponível em: http://enciclopedia.itaucultural.org.br/termo3229/minimalismo. Acesso em: 10 jan. 2021.

MORIN, Edgar. Sobre a estética. São Paulo: Pro Saber; 2017.

MUNIZ, Vik. Gallery. New York; 2020. Disponível em: http://vikmuniz.net/pt/. Acesso em: 13 set. 2020. 
SALLES, Cecilia Almeida. Gesto inacabado: processo de criação artística. São Paulo: FAPESP; Annablume; 1998.

SANFELICE, Sabrina. Diálogos contemporâneos entre arte e fotografia: um percurso pelas obras de Vik Muniz. 2011. 199 f. Dissertação (Mestrado em Artes) Instituto de Artes, Universidade Estadual de Campinas, Campinas; 2011.

STARTE. Artista plástico Vik Muniz revela curiosidades de seus trabalhos. Direção: Luiz Claudio Latge. Produção: Roberto Werteman. Rio de Janeiro: TV Globo; 2009. 1 vídeo (22:39 min). Disponível em:

https://www.youtube.com/watch?v=B3vTbF62PCk. Acesso em: 3 out. 2020. 